\title{
Deleterious role of hepatitis B virus infection in therapeutic response among patients with rheumatoid arthritis in a clinical practice setting: a case-control study
}

Yu-Lan Chen ${ }^{1}$, Jian-Zi Lin ${ }^{1}$, Ying-Qian Mo ${ }^{1}$, Jian-Da Ma', Qian-Hua Li' ${ }^{1}$ Xiao-Ying Wang ${ }^{1}$, Ze-Hong Yang ${ }^{2}$, Tao Yan ${ }^{3}$, Dong-Hui Zheng ${ }^{1 *}$ and Lie Dai ${ }^{{ }^{*}}$

\begin{abstract}
Background: Previous studies have revealed that hepatitis B virus (HBV) infection may be associated with rheumatoid arthritis (RA), while there are no further clinical studies regarding the role of HBV infection in RA progression during disease-modifying anti-rheumatic drug (DMARD) therapy. Here, we aimed to explore the influence of HBV infection on radiographic and clinical outcomes among patients with RA in a clinical practice setting.

Methods: Thirty-two consecutive patients with RA (Disease Activity Score 28-joint assessment based on C-reactive protein (DAS28-CRP) 22.6) with chronic HBV infection (CHB) were retrospectively recruited as the CHB group and 128 age-matched, sex-matched, and disease activity-matched contemporary patients with RA without CHB were included in the non-CHB group. Clinical data were collected at baseline and visits at month 1, 3, 6, and 12. The therapeutic target was defined as DAS28-CRP $<2.6$ in all patients or $<3.2$ in patients with long disease duration ( $>24$ months). The primary outcome was the percentage of patients with one-year radiographic progression (a change in modified total Sharp score $\geq 0.5$ ).

Results: Compared with the non-CHB group, a significantly higher percentage of patients with one-year radiographic progression was observed in the CHB group (53\% vs. 17\%, $p<0.001$ ), with smaller proportions of patients achieving therapeutic target at month 6 and month 12 (53\% vs. 82\% and 53\% vs. 75\%, both $p<0.05$ ), remission at month 6 (DAS28-CRP $<2.6,50 \%$ vs. 72\%, $p=0.039$ ), and American College of Rheumatology (ACR)20/50 responses and good or moderate European League Against Rheumatism (EULAR) responses mainly at month 6 and 12 (all $p<0.05$ ). Multivariate logistic regression analysis revealed that CHB status was significantly associated with one-year radiographic progression and failure to achieve therapeutic target within 6 months. HBV reactivation occurred in 34\% of patients with CHB during one-year follow up, with two patients suffering hepatitis flare.
\end{abstract}

Conclusions: HBV infection may play a deleterious role in radiographic and clinical outcomes in patients with RA, and HBV reactivation should be paid close attention during immunosuppressive therapy.

Keywords: Hepatitis B virus, Rheumatoid arthritis, Radiographic progression, Clinical response

\footnotetext{
* Correspondence: zhengouyang@sina.com; dailie@mail.sysu.edu.cn

'Department of Rheumatology, Sun Yat-Sen Memorial Hospital, Sun Yat-Sen

University, Guangzhou 510120, People's Republic of China

Full list of author information is available at the end of the article
} 


\section{Background}

Rheumatoid arthritis (RA) is a systemic autoimmune disease affecting millions of people worldwide, which is characterized by synovitis with bone and cartilage destruction. The etiology of RA remains largely unknown [1]. Genetic predisposition is not sufficient to explain RA development, and environmental triggers, especially infectious agents such as Epstein-Barr virus, cytomegalovirus, and Proteus mirablis, have been reported to be linked with RA pathogenesis [2]. New evidence shows that the oral and gut microbiomes are perturbed in patients with RA and partly normalized after RA treatment, suggesting a significant role of microbiomes in RA [3]. Despite these studies, the identity and pathogenicity of most factors implicating a role in RA are not yet clear.

Hepatitis $B$ virus (HBV) infection continues to be one of worldwide leading disease burdens. About 248 million (3.61\%) individuals globally have been reported as HBV surface antigen (HBsAg)-positive, with 74 million Chinese patients $(5.49 \%)$ in 2010 [4]. HBV primarily infects human hepatocytes, and also leads to a series of extrahepatic manifestations or diseases such as polyarthritis, glomerulonephritis, polyarteritis nodosa, and cryoglobulinemia [5]. HBV-related antigens and nucleic acids have been demonstrated in a variety of extrahepatic tissues, including lymph nodes, kidney, skin, colon, stomach, testis, and ovaries [6]. Only a few studies have revealed a possibility of the presence of HBV proteins and DNA in synovial tissues from patients with HBV infection [7, 8]. Surprisingly, several patients with concurrent HBV infection who fulfilled the diagnostic criteria of American College of Rheumatology (ACR) for RA were shown to have disease resolved by anti-HBV treatment $[9,10]$. Additionally, prior studies have documented higher serum HBsAg positivity in patients with RA than in non-RA controls [11, 12]. Our previous studies identified $11.2 \% \mathrm{HBsAg}$ positivity in Chinese patients with RA and HBV reactivation as a common but tricky complication in HBsAg-positive patients with RA undergoing immunosuppressive therapy [13, 14]. Thus, HBV infection and RA are somehow linked. However, until now, no longitudinal studies have examined the role of HBV infection in disease progression during RA treatment. Therefore, the aim of the present study was to explore the influence of $\mathrm{HBV}$ infection on therapeutic response and the safety of immunosuppressive therapy in patients with RA with $\mathrm{CHB}$.

\section{Methods}

\section{Study patients and design}

Patients with RA who fulfilled the 1987 revised criteria of the ACR [15] or the 2010 ACR/European League Against Rheumatism (EULAR) criteria for the classification of RA [16] were retrospectively recruited between June 2012 and August 2016 at Sun Yat-Sen Memorial Hospital from a prospective cohort, as described in our previous study [17]. All patients were treated according to the "treat-to-target" strategy [18, 19] and completed at least one year of follow up. Consecutive patients with RA with HBsAg positivity persisting in serum for more than 6 months were recruited as the $\mathrm{CHB}$ group. Each patient with RA in the CHB group was matched by age ( \pm 5 years), sex, and disease activity at baseline to four subjects without HBsAg positivity or HBV DNA in serum, who comprised the non-CHB group. The timing of baseline for the four matched patients in the non- $\mathrm{CHB}$ group was as close as possible to baseline for the corresponding patient in the $\mathrm{CHB}$ group. Other inclusion criteria were patients aged $\geq 18$ years and patients with active disease defined as Disease Activity Score 28-joint assessment (DAS28) with four variables including C-reactive protein (DAS28-CRP) $\geq 2$.6. The exclusion criteria were elevated aminotransferase at baseline; other overlapping autoimmune diseases (e.g. systemic lupus erythematosus, scleroderma, dermatomyositis, polyarteritis nodosa, cryoglobulinaemia, nephritis); Wilson's disease, steatohepatitis, hemochromatosis, Schistosomiasis japonica, or drug-induced hepatitis; concomitant infection with hepatitis $\mathrm{C}$ virus, hepatitis $\mathrm{D}$ virus, or human immunodeficiency virus; other serious infection, organ dysfunction, or malignancy; and lactating or pregnant women. This study was conducted in compliance with the Helsinki Declaration. Due to the retrospective nature of the study, informed consent was waived. The study was approved by the Medical Ethics Committee of Sun YatSen Memorial Hospital (identifier SYSEC-KY-KS-011).

\section{Treatment and clinical data collection}

All patients were treated according to the 2008/2012 ACR [20, 21] and the 2010/2013 EULAR [18, 19] recommendations for the management of RA. The therapeutic target was defined as DAS28-CRP $<2.6$ in all patients or $<3.2$ in patients with long disease duration ( $>24$ months) $[18,19]$. Available clinical data on patients with RA were collected in this study at baseline and at visits at months $1,3,6$, and 12 , as described before [17], including 28joint tender and swollen joint counts (TJC28 and SJC28), patient and provider global assessment of disease activity (PtGA and PrGA, respectively), pain visual analog scale (pain VAS), the Stanford Health Assessment Questionnaire (HAQ), erythrocyte sedimentation rate (ESR), CRP, rheumatoid factor (RF), and anti-cyclic citrullinated peptide antibody (ACPA). Besides DAS28CRP, disease activity was also assessed using the Simplified Disease Activity Index (SDAI), the Clinical Disease Activity Index (CDAI), and the Routine Assessment of Patient Index Data 3 (RAPID3) [22]. Cumulative doses 
of oral glucocorticosteroids (GCs) and disease-modifying anti-rheumatic drugs (DMARDs) were recorded during one-year follow up. GC doses were converted to a prednisone-equivalent dose.

Serological markers of HBV infection, including HBsAg, $\mathrm{HBV}$ e antigen ( $\mathrm{HBeAg})$, the corresponding antibodies to these antigens (anti-HBs and anti-HBe, respectively), and antibodies to HBV core antigen (anti-HBc), were tested in all patients with RA using enzyme-linked immunosorbent assay (Zhongshan Biotechnology CO., LTD, Guangdong, China) or electrochemluminescence-immunoassay (Roche Diagnostics, Mannheim, Germany). HBV DNA was measured using a commercially available quantitative realtime polymerase chain reaction kit (Da An Gene Co., Ltd. of Sun Yat-Sen University, Guangdong, China), with the lowest detection threshold of $500 \mathrm{IU} / \mathrm{mL}$. Liver function including alanine aminotransferase (ALT, U/L, normal range 5-40 U/L) and aspartate transaminase (AST, U/L, normal range $5-40 \mathrm{U} / \mathrm{L}$ ) was tested at each visit during follow up. HBV serological markers and HBV DNA levels were evaluated in all patients with RA at baseline and every 1-3 months during follow up in the $\mathrm{CHB}$ group. These parameters in the non-CHB group were reexamined if aminotransferase was elevated during follow up. Antiviral prophylaxis by entecavir or tenofovir was suggested for all patients with RA with $\mathrm{CHB}$ before RA treatment. Moreover, serum levels of soluble matrix metalloproteinase (MMP-3) were tested as described before [23]. The normal ranges of serum MMP-3 concentrations were $18-60 \mathrm{ng} / \mathrm{mL}$ (women) and $24-120 \mathrm{ng} / \mathrm{mL}$ (men).

\section{Radiographic assessments}

Radiographs of the bilateral hands and wrists (anteroposterior view) of all patients were performed at baseline and month 12. The Sharp/van der Heijde-modified total Sharp score (mTSS), joint erosion (JE), and joint space narrowing (JSN) were scored by two experienced observers (MJD from the Department of Rheumatology and $\mathrm{YZH}$ from the Department of Radiology), who were blinded to the patients' clinical data. As described previously [17], reliability and agreement were assessed based on the intra-class correlation coefficient (ICC): the mean ICC for inter-observer agreement was 0.950 . Bony erosion was defined as a cortical break identified on radiography [24]. Radiographic progression was defined as a change in mTSS $(\Delta \mathrm{mTSS}) \geq 0.5$ units [25], and rapid radiographic progression (RRP) was defined as $\Delta$ mTSS $\geq 5$ units from baseline to month 12 [26].

\section{Outcome assessments}

The primary outcome was the percentage of patients with one-year radiographic progression. The secondary outcomes were determined at each visit. These were the percentages of patients achieving therapeutic target and remission, rates of EULAR responses and ACR20/50/70 responses [27], and changes in disease activity indicators.

\section{Safety assessments}

Side effects were recorded and evaluated at each visit. Neutropenia was defined as neutrophil count $<2.0 \times$ $10^{9} / \mathrm{L}$. HBV reactivation was defined as the reappearance of HBsAg in a patient with resolved HBV infection, the detection of previously undetectable HBV DNA or $>1$ $\log 10$ (10-fold) IU/mL increase in serum HBV DNA, and rise in HBV DNA level above an arbitrary cutoff (for example, 20,000 IU) in patients with biochemical worsening [28-30]. A hepatitis flare was determined to be present when ALT was greater than two times the upper limit of the normal range (ULN) [30].

\section{Statistical analysis}

Statistical analyses were performed using IBM SPSS Statistics version 20.0 software (IBM, Armonk, NY, USA). Descriptive statistics (median, interquartile range (IQR) or 5th/95th percentile ranges) were calculated for continuous variables and categorical variables were presented as frequencies and percentages. Conditional logistic regression analysis was used to compare continuous and categorical variables between the $\mathrm{CHB}$ group and the non-CHB group, and odds ratios (ORs) and 95\% confidence intervals (CIs) were calculated to identify risk factors for one-year radiological progression and failure to achieve therapeutic target within 6 months. Variables were included in the equation when the $p$ value was < 0.05 or removed when the $p$ value was $>0.10$, following the step-forward selection rule. A two tailed $p$ value $<0.05$ was considered statistically significant.

\section{Results}

\section{Demographic characteristics of patients with RA at baseline}

A total of 32 patients with RA with $\mathrm{CHB}$ were included in the study, of whom 27 (84\%) were female. There were $72 \%$ of patients who were both RF and ACPA positive, and $78 \%$ of patients had bony erosion at baseline. Eleven (34\%) patients were treatment-naïve, without previous GC or DMARD therapy for 6 months before enrollment. Fourteen (44\%) patients had a level of HBV DNA above $500 \mathrm{IU} / \mathrm{mL}$, of whom $11(34 \%)$ had levels above $10^{3} \mathrm{IU} /$ $\mathrm{mL}$ and $8(25 \%)$ had levels above $10^{4} \mathrm{IU} / \mathrm{mL}$, all with normal liver function. A total of 128 age-matched, sexmatched, and baseline disease activity-matched RA controls in the non-CHB group were compared with patients with RA with CHB. There was no significant difference in baseline demographic and clinical characteristics between groups, except for significantly higher levels of JE subscore and mTSS, and significantly greater proportions of patients using sulfasalazine (SSZ) and hydroxychloroquine 
(HCQ) in the previous 6 months before enrollment in the CHB group (both $p<0.05$, Table 1 ).

\section{Comparison of treatment after enrollment}

Initial treatment after enrollment and therapy adjustment were according to the "treat-to-target" strategy and patient's willingness. There was no significant difference between groups in the initial therapy using GCs, methotrexate (MTX), iguratimod, or biologic agents after enrollment (all $p>0.05$, Table 2). Compared with the non$\mathrm{CHB}$ group, significantly higher percentages of patients in the CHB group took SSZ and HCQ ( $44 \%$ vs. $2 \%$ and $75 \%$ vs. $11 \%$, respectively; both $p<0.001$ ), while a significantly smaller proportion of patients with $\mathrm{CHB}$ took leflunomide (LEF) (16\% vs. $84 \%, p<0.001)$. Accordingly, patients in the CHB group received significantly higher cumulative doses of SSZ, HCQ, and cyclosporin A (CysA), while taking significantly lower cumulative doses of methotrexate (MTX) and LEF both within the initial 6 months after enrollment and during one-year follow up (all $p<0.05$ ). Combined DMARDs were used in 31 (97\%) patients in the $\mathrm{CHB}$ group and 125 (98\%) in the non-CHB group. Compared with the non-CHB group, a greater proportion of $\mathrm{CHB}$ patients used the regimen of MTX combined with SSZ and HCQ (34\% vs. $1 \%, p<$ 0.001), while a smaller percentage of patients in the CHB group used the regimen of MTX combined with LEF ( $9 \%$ vs. $72 \%, p<0.001$ ). Six $(19 \%)$ patients in the $\mathrm{CHB}$ group and $38(30 \%)$ in the non-CHB group were treated with a combination of conventional synthetic DMARDs (csDMARDs) and biologic agents (tocilizumab, infliximab, or recombinant human tumor necrosis factor- $\alpha$ receptor-II (Yi Sai Pu, biosimilar)).

Antiviral prophylaxis by entecavir or tenofovir was suggested for all patients with RA with CHB. However, due to economic reasons, only 14 (44\%) patients finally accepted, of whom 5 (36\%) chose lamivudine, 6 (43\%) adefovir, and only 3 (21\%) entecavir. Notably, there were no significant differences in GC therapy, DMARD therapy, or cumulative doses of the medications after enrollment between patients with and without antiviral prophylaxis. Antiviral therapy was commenced or switched to agents with a high barrier to resistance, such as entecavir or tenofovir, when HBV reactivation occurred. In addition, liver function was closely monitored as frequently as 2 to 4 weeks and GC, MTX, or LEF therapies were tapered or withdrawn, especially if hepatitis flare occurred.

\section{Patients with RA with CHB had more pronounced radiographic progression at month 12}

Compared with the non-CHB group, there was a significantly higher percentage of patients in the $\mathrm{CHB}$ group experiencing one-year radiographic progression (53\% vs.
$17 \%, p<0.001)$, with a similar trend in RRP ( $16 \%$ vs. $5 \%$, $p=0.059)$. Significantly higher levels of JE subscore, JSN subscore, and mTSS at month 12 were observed and there were more increases in JE subscore and MTSS in the $\mathrm{CHB}$ group than those in the non- $\mathrm{CHB}$ group (all $p$ $<0.05)$. The cumulative probability distribution of radiographic change from baseline to month 12 in patients with RA in both groups and the space between the curves indicated there was a significantly higher percentage of patients with $\mathrm{CHB}$ who had one-year radiographic progression (Fig. 1a-c).

\section{Patients with RA with CHB achieved a lower level of clinical response}

At month 6, the proportions of patients achieving therapeutic target (53\% vs. $82 \%, p=0.003)$ and remission $(50 \%$ vs. $72 \%, p=0.039)$ were significantly smaller in the $\mathrm{CHB}$ group than those in the non-CHB group, with a similar trend of achieving therapeutic target and remission at month $12(53 \%$ vs. $75 \%, p=0.034$ and $44 \%$ vs. $63 \%, p=0.077$, respectively) (Fig. 2a, b). The percentages of ACR20 and ACR50 responders were also significantly lower in the $\mathrm{CHB}$ group versus the non-CHB group at month 6 (56\% vs. $81 \%, p=0.013$ and $47 \%$ vs. $70 \%, p=$ 0.029, respectively) (Fig. 2c, d). Additionally, compared with the non-CHB group, the percentage of patients achieving good or moderate EULAR response was significantly lower in the $\mathrm{CHB}$ group at month 3 (75\% vs. $91 \%, p=0.038)$ and month $12(69 \%$ vs. $91 \%, p=0.004)$; a significantly smaller proportion of patients achieving a good EULAR response was observed in the CHB group at month 6 (56\% vs. 79\%, $p=0.022)$ and month $12(53 \%$ and $74 \%, p=0.041$ ) (Fig. 2e, f).

The results of dynamic disease activity indicators during one-year follow up are shown in Fig. 2g-n. Disease activity indicators, except for ESR, TJC28, HAQ, were significantly higher in the $\mathrm{CHB}$ group than those in the control group mainly at month 6 and month 12 (all $p<$ $0.05)$. An additional file shows the other clinical responses that were not demonstrated in Fig. 2 (Additional file 1). Moreover, a significantly higher serum MMP-3 level was observed in female patients from the $\mathrm{CHB}$ group compared with that in the non- $\mathrm{CHB}$ group at month 12 ( $p=0.020$, Fig. 2o). Regardless of gender, a similar trend in the serum MMP-3 level was also seen at month 6 ( $p=0.086$, Additional file 1).

\section{Risk factors for one-year radiographic progression and failure to achieve therapeutic target within 6 months}

To determine risk factors for one-year radiographic progression, univariate logistic regression analysis was performed on variables including baseline characteristics, CHB status, and RA medications after enrollment (including categories of medications, one-year cumulative 
Table 1 Demographic and disease characteristics at baseline

\begin{tabular}{|c|c|c|c|}
\hline Parameters & $\begin{array}{l}\text { CHB group } \\
(n=32)\end{array}$ & $\begin{array}{l}\text { Non-CHB group } \\
(n=128)\end{array}$ & $p$ value \\
\hline \multicolumn{4}{|l|}{ Matched parameters } \\
\hline Female, $n(\%)$ & $27(84)$ & 108 (84) & 1.000 \\
\hline Age (years) & $49(38-56)$ & $49(38-57)$ & 0.964 \\
\hline DAS28-CRP & $4.6(3.5-5.0)$ & $4.6(3.8-5.3)$ & 0.791 \\
\hline \multicolumn{4}{|l|}{ Demographic characteristics } \\
\hline Age of onset (years) & $44(31-52)$ & $45(33-53)$ & 0.948 \\
\hline $\begin{array}{l}\text { Disease duration } \\
\text { (months) }\end{array}$ & $36(9-113)$ & $36(12-84)$ & 0.805 \\
\hline $\begin{array}{l}\text { Short duration } \\
\text { ( }<6 \text { months) }\end{array}$ & $3(9)$ & $19(15)$ & 0.476 \\
\hline $\begin{array}{l}\text { Intermediate duration } \\
\text { (6-24 months) }\end{array}$ & $12(38)$ & $39(30)$ & 0.501 \\
\hline $\begin{array}{l}\text { Long duration } \\
\text { (>24 months) }\end{array}$ & $17(53)$ & $70(55)$ & 0.887 \\
\hline \multicolumn{4}{|l|}{ Disease characteristics } \\
\hline TJC28 & $6(2-10)$ & $6(3-10)$ & 0.914 \\
\hline SJC28 & $4(1-8)$ & $4(2-6)$ & 0.523 \\
\hline PainVAS & $4(2-5)$ & $4(3-6)$ & 0.131 \\
\hline PtGA & $5(3-6)$ & $5(3-6)$ & 0.355 \\
\hline PrGA & $5(3-5)$ & $5(3-6)$ & 0.276 \\
\hline $\mathrm{HAQ}$ & $0.6(0-1.3)$ & $0.6(0.1-1.2)$ & 0.888 \\
\hline CRP (mg/L) & $12.1(3.8-44.2)$ & $12.1(4.8-32.0)$ & 0.543 \\
\hline ESR $(\mathrm{mm} / \mathrm{h})$ & $36(20-62)$ & $50(24-75)$ & 0.162 \\
\hline RF positivity, $n(\%)$ & $23(72)$ & $96(75)$ & 0.746 \\
\hline ACPA positivity, $n(\%)$ & $23(72)$ & $101(79)$ & 0.448 \\
\hline SDAl & $\begin{array}{l}22.1(13.6- \\
31.3)\end{array}$ & $21.2(14.6-29.3)$ & 0.320 \\
\hline CDAI & $19(12-28)$ & $20(13-26)$ & 0.332 \\
\hline RAPID3 & $3.3(2.1-4.6)$ & $3.6(2.7-5.2)$ & 0.128 \\
\hline MMP-3 (ng/mL) & $184(86-453)$ & $155(86-358)$ & 0.440 \\
\hline \multicolumn{4}{|l|}{ Liver function } \\
\hline AST (U/L) & $18(14-25)$ & $16(14-21)$ & 0.630 \\
\hline $\mathrm{ALT}(\mathrm{U} / \mathrm{L})$ & $18(12-29)$ & $15(10-21)$ & 0.769 \\
\hline \multicolumn{4}{|l|}{ Radiographic status } \\
\hline Bony erosions, $n(\%)$ & $25(78)$ & $96(75)$ & 0.742 \\
\hline JSN subscore & $5.5(0-18.8)$ & $3.0(1.0-9.8)$ & 0.078 \\
\hline JE subscore & $6.0(1.0-22.0)$ & $4.0(0.3-10.0)$ & 0.009 \\
\hline mTSS & $11.0(1.3-36.3)$ & $8.0(2.0-20.8)$ & 0.021 \\
\hline \multicolumn{4}{|l|}{ Previous medications, $n$ (\%) } \\
\hline Treatment-naïve ${ }^{\mathrm{b}}$ & $11(34)$ & $55(43)$ & 0.431 \\
\hline GCs & $14(44)$ & $48(38)$ & 0.562 \\
\hline MTX & $16(50)$ & $49(38)$ & 0.283 \\
\hline
\end{tabular}

Table 1 Demographic and disease characteristics at baseline (Continued)

\begin{tabular}{|c|c|c|c|}
\hline Parameters & $\begin{array}{l}\text { CHB group } \\
(n=32)\end{array}$ & $\begin{array}{l}\text { Non-CHB group } \\
(n=128)\end{array}$ & $p$ value $e^{a}$ \\
\hline LEF & $6(19)$ & $34(27)$ & 0.417 \\
\hline SSZ & $4(13)$ & $1(1)$ & 0.005 \\
\hline $\mathrm{HCQ}$ & $10(31)$ & $12(9)$ & 0.006 \\
\hline CysA & 1 (3) & $5(4)$ & 0.853 \\
\hline Biologic agents & $1(3)$ & $3(2)$ & 0.821 \\
\hline \multicolumn{4}{|c|}{$\begin{array}{l}\text { Data are presented as median (interquartile range (IQR)) or number } \\
\text { (percentage (\%)) } \\
\text { ACPA anti-cyclic citrullinated peptide antibody, ALT alanine aminotransferase, } \\
\text { AST aspartate transaminase, CDAI Clinical Disease Activity Index, CHB chronic } \\
\text { hepatitis B virus infection, CRP C-reactive protein, CysA cyclosporin A, DAS28 } \\
\text { Disease Activity Score 28-joint assessment, DMARD disease-modifying anti- } \\
\text { rheumatic drug, ESR erythrocyte sedimentation rate, GC glucocorticosteroid, } \\
H A Q \text { Stanford Health Assessment Questionnaire, } H C Q \text { hydroxychloroquine, JE } \\
\text { joint erosion, JSN joint space narrowing, LEF leflunomide, mTSS modified total } \\
\text { Sharp score, MMP-3 matrix metalloproteinase-3, MTX methotrexate, NA not } \\
\text { applicable, Pain VAS pain visual analog scale, PrGA provider global assessment of } \\
\text { disease activity, PtGA patient global assessment of disease activity, RA rheumatoid } \\
\text { arthritis, RAPID3 Routine Assessment of Patient Index Data 3, RF rheumatoid } \\
\text { factor, SDAI Simplified Disease Activity Index, SJC28 28-joint swollen joint counts, } \\
\text { SSZ sulfasalazine, TJC28 28-joint tender joint count } \\
\text { aCompared between the CHB group and the non-CHB group using conditional } \\
\text { logistic regression analysis: bold } p \text { values are significant } \\
\text { bWithout glucocorticosteroid or DMARD therapy for } 6 \text { months } \\
\text { before enrollment }\end{array}$} \\
\hline
\end{tabular}

doses of medications, and different regimens of combined therapies) (Table 3). The results revealed that CHB status (OR 3.129, 95\% CI 1.661-5.895; $p<0.001$ ), higher baseline mTSS (OR 1.016, 95\% CI 1.006-1.026; $p$ $=0.001)$, and higher one-year cumulative dose of GCs (OR 1.000282, 95\% CI 1.000067-1.000497, $p=0.010$ ) were significant factors for one-year radiographic progression. In bivariate analyses that adjusted for baseline mTSS and one-year cumulative dose of GCs, one factor at a time, CHB status was still positively associated with one-year radiographic progression (OR 2.610 and OR 2.881 , respectively; both $p<0.01$ ). Moreover, multivariate logistic regression analysis that adjusted for all significant factors from univariate analyses showed that $\mathrm{CHB}$ status was independently associated with one-year radiographic progression (OR 2.403, 95\% CI 1.2184.743; $p=0.011$ ).

Both ACR and EULAR recommendations for the management of RA emphasize tight control of disease activity and attaining therapeutic target within 6 months [19, 21]. Therefore, logistic regression analysis was also performed to determine risk factors for failure to achieve therapeutic target within 6 months (Table 4). The results of univariate logistic regression analysis revealed that CHB status (OR 3.077, 95\% CI 1.349-7.017; $p=0.008$ ), being medication-naïve (OR $0.300,95 \%$ CI $0.102-0.881$; $p=0.029$ ), MTX therapy (OR 0.266, 95\% CI 0.099$0.716 ; p=0.009$ ), a regimen of MTX combined with LEF (OR 0.365, 95\% CI 0.155-0.861; $p=0.021$ ), 6-month cumulative dose of MTX (OR 0.997, 95\% CI 0.993- 
Table 2 Medications after enrollment

\begin{tabular}{|c|c|c|c|}
\hline Medication & $\begin{array}{l}\text { CHB group } \\
(n=32)\end{array}$ & $\begin{array}{l}\text { Non-CHB group } \\
(n=128)\end{array}$ & $p$ value $^{a}$ \\
\hline \multicolumn{4}{|l|}{ Initial medications, $n(\%)$} \\
\hline GCs & $23(72)$ & $89(70)$ & 0.817 \\
\hline$<5$ mg/day & $1(3)$ & $3(2)$ & 0.821 \\
\hline$\geq 5, \leq 10 \mathrm{mg} /$ day & $19(59)$ & $81(63)$ & 0.715 \\
\hline day $>10, \leq 20 \mathrm{mg} /$ & $2(6)$ & $4(3)$ & 0.462 \\
\hline$>20$ mg/day & $1(3)$ & $1(1)$ & 0.357 \\
\hline MTX & $28(87)$ & $121(95)$ & 0.217 \\
\hline$\leq 10 \mathrm{mg} /$ week & $21(66)$ & $79(62)$ & 0.715 \\
\hline $\begin{array}{l}>10, \leq 15 \mathrm{mg} / \\
\text { week }\end{array}$ & $6(19)$ & $40(31)$ & 0.217 \\
\hline$>15$ mg/week & $1(3)$ & $2(2)$ & 0.606 \\
\hline LEF & $5(16)$ & $107(84)$ & $<0.001$ \\
\hline SSZ & $14(44)$ & $2(2)$ & $<0.001$ \\
\hline $\mathrm{HCQ}$ & $24(75)$ & $14(11)$ & $<0.001$ \\
\hline CysA & $4(13)$ & $4(3)$ & 0.062 \\
\hline Iguratimod & $1(3)$ & $10(8)$ & 0.415 \\
\hline Biologic agents & $6(19)$ & $38(30)$ & 0.273 \\
\hline Tocilizumab & $4(13)$ & $30(23)$ & 0.234 \\
\hline Yi Sai Pu & $2(6)$ & $5(4)$ & 0.606 \\
\hline Infliximab & $0(0)$ & $3(2)$ & NA \\
\hline \multicolumn{4}{|c|}{ Six-month cumulative dose of medications ${ }^{\mathrm{b}}(\mathrm{mg})$} \\
\hline GCs & $900(0-1406)$ & $1069(0-1556)$ & 0.506 \\
\hline MTX & $260(201-315)$ & $288(260-348)$ & 0.024 \\
\hline LEF & $0(0-0)$ & $\begin{array}{l}1800(1500- \\
3263)\end{array}$ & $<0.001$ \\
\hline SSZ & $0(0-270,000)$ & $0(0-0)$ & $<0.001$ \\
\hline $\mathrm{HCQ}$ & $\begin{array}{l}54,000(3000- \\
72,000)\end{array}$ & $0(0-0)$ & $<0.001$ \\
\hline CysA ${ }^{c}$ & $0(0-19,515)$ & $0(0-4500)$ & 0.020 \\
\hline Iguratimod ${ }^{c}$ & $0(0-2625)$ & $0(0-9000)$ & 0.330 \\
\hline Tocilizumab $^{c}$ & $0(0-1880)$ & $0(0-2400)$ & 0.218 \\
\hline Yi Sai Pu & $0(0-600)$ & $0(0-0)$ & 0.606 \\
\hline Infliximab ${ }^{c}$ & $0(0-0)$ & $0(0-0)$ & NA \\
\hline \multicolumn{4}{|c|}{ One-year cumulative dose of medications (mg) } \\
\hline GCs & $1800(0-2790)$ & $1744(0-2475)$ & 0.418 \\
\hline MTX & $520(413-650)$ & $585(520-715)$ & 0.023 \\
\hline LEF & $0(0-0)$ & $\begin{array}{l}3600 \\
(2719-6600)\end{array}$ & $<0.001$ \\
\hline SSZ & $68,000(0-536,000)$ & $0(0-0)$ & $<0.001$ \\
\hline HCQ & $\begin{array}{l}90,000 \\
(3000-144,000)\end{array}$ & $0(0-0)$ & $<0.001$ \\
\hline
\end{tabular}

Table 2 Medications after enrollment (Continued)

\begin{tabular}{llll}
\hline Medication & $\begin{array}{l}\text { CHB group } \\
(\mathrm{n}=32)\end{array}$ & $\begin{array}{l}\text { Non-CHB group } \\
(\mathrm{n}=128)\end{array}$ & $p$ value $^{\mathrm{a}}$ \\
\hline CysA $^{c}$ & $0(0-37,575)$ & $0(0-12,825)$ & $\mathbf{0 . 0 1 6}$ \\
Iguratimod $^{c}$ & $0(0-5775)$ & $0(0-9000)$ & 0.393 \\
Tocilizumab $^{c}$ & $0(0-1880)$ & $0(0-2800)$ & 0.184 \\
Yi Sai Pu $^{c}$ & $0(0-600)$ & $0(0-0)$ & 0.606 \\
Infliximab $^{c}$ & $0(0-0)$ & $0(0-0)$ & $\mathrm{NA}$ \\
\hline
\end{tabular}

Data are presented as median (interquartile range (IQR)) or number (percentage (\%)) unless stated otherwise

CHB chronic hepatitis B virus (HBV) infection, CysA cyclosporin A, GC glucocorticosteroid, HCQ hydroxychloroquine, LEF leflunomide, MTX methotrexate, NA not applicable, SSZ sulfasalazine

${ }^{a}$ Compared between the $\mathrm{CHB}$ group and the non-CHB group using conditional logistic regression analysis: bold $p$ values are significant

${ }^{b}$ Within the initial 6 months after enrollment

'Data were analyzed as median (5th/95th percentile ranges) due to the small number of patients using these medications

1.000; $p=0.049$ ), and 6-month cumulative dose of CysA (OR 1.000077, 95\% CI 1.000011-1.000143; $p=0.023$ ) were recognized as significant factors for failure to achieve therapeutic target within 6 months. Bivariate analyses that adjusted for the significant factors in the univariate analyses, one factor at a time, demonstrated that $\mathrm{CHB}$ status was always an independent risk factor (OR 2.722-3.077, $p=0.019-0.008$ ). Further multivariate logistic regression analysis was performed by adjusting for all significant factors in the univariate analyses. Due to the multicollinearity between MTX therapy and 6month cumulative dose of MTX, two multivariate models were set up respectively and the results of both models showed that $\mathrm{CHB}$ status remained significantly associated with failure to achieve therapeutic target within 6 months (MTX therapy model, OR 2.617, 95\% CI 1.140-6.007, $p=0.023$; 6-month cumulative dose of MTX model, OR 2.844, 95\% CI 1.245-6.498, $p=0.013$ ).

\section{Safety}

Table 5 presents an overview of side effects during oneyear follow up. Infections occurred in $16 \%$ of patients with $\mathrm{CHB}$ and $13 \%$ of patients in the non-CHB group. The most common infections were respiratory tract infection, with one patient (3\%) in the CHB group and six paitents (5\%) in the control group diagnosed as pneumonia respectively. One patient in the non-CHB group suffered from herpes zoster 7 months after initiation with tocilizumab. There was no significant difference between groups in the incidence of infections, trichomadesis, neutropenia, or gastrointestinal discomfort (all $p>0.05$ ). No deaths occurred due to these side effects in this study.

The main side effects of RA treatment on HBV infection were HBV reactivation and aminotransferase elevation. No patient in the non-CHB group developed HBV reactivation. However, $34 \%$ of $\mathrm{CHB}$ patients developed 

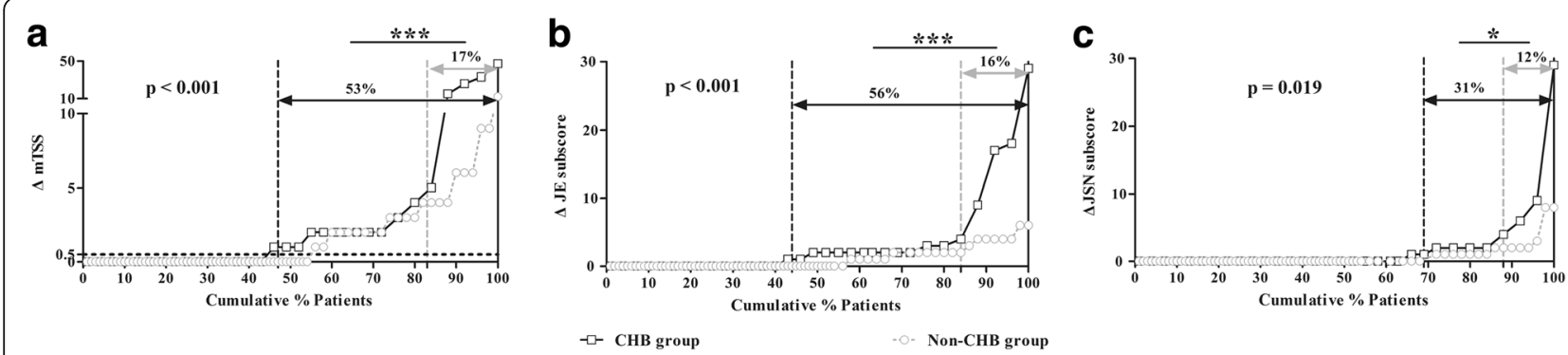

Fig. 1 One-year radiographic change in patients with rheumatoid arthritis (RA) in the chronic hepatitis B virus infection (CHB) group and the nonCHB group. Comparison of cumulative probability of $\triangle \mathrm{mTSS}(\mathbf{a}), \triangle \mathrm{JSN}$ subscore (b) and $\triangle \mathrm{JE}$ subscore (c) during one-year follow up between the CHB group and the non-CHB group: ${ }^{*} p<0.05,{ }^{* *} p<0.01,{ }^{* * *} p<0.001$. JE, joint erosion; JSN, joint space narrowing; mTSS, modified total Sharp score

virus reactivation, of whom $8(72 \%)$ refused to accept antiviral prophylaxis, with hepatitis flare occurring in 2 patients $(6 \%)$ during follow up. There was no significant difference in the incidence of aminotransferase elevation between groups $(19 \%$ vs. $31 \%, p>0.05)$. A flowchart of HBV reactivation and hepatitis flare occurring in patients with CHB is shown in Additional file 2. Fortunately, serum HBV DNA level and aminotransferase in all patients with RA returned to undetectable or normal after commencing antiviral therapy or adjusting GC, MTX, or LEF therapy. No liver cirrhosis, liver failure, or HBV-related deaths occurred during follow up in this study.

\section{Discussion}

In this study, we performed a retrospective case-control study to investigate the influence of HBV infection on therapeutic response among patients with RA in a clinical practice setting. The Sharp/van der Heijde score showed that patients with RA with $\mathrm{CHB}$ suffered more pronounced one-year radiographic progression than the non-CHB group. Compared with the control group, smaller proportions of patients with $\mathrm{RA}$ with $\mathrm{CHB}$ achieved therapeutic target and remission, and the trend was also seen in attaining ACR20/50 responses and good or moderate EULAR responses, mainly at month 6 and month 12. Conditional logistic regression analysis showed that $\mathrm{CHB}$ status was independently associated with one-year radiographic progression. Both ACR and EULAR recommendations for the management of RA emphasize that therapeutic target should be attained within 6 months $[19,21]$. Thus, conditional logistic regression analysis was further performed and the result showed that CHB status was also significantly associated with failure to achieve therapeutic target within 6 months. Therefore, HBV infection may play a deleterious role in radiographic and clinical outcomes in patients with RA. To our knowledge, this is the first study to investigate the role of $\mathrm{HBV}$ infection in therapeutic response among patients with RA in clinical practice, which revealed that HBV infection is implicated in RA progression.

HBV infection was complicated due to extrahepatic manifestations including polyarthritis mainly affecting small joints, which seemed to mimic that of RA and was considered to be immune-complex mediated [31]. Use of recombinant HBsAg could induce the appearance of RA-like symptoms [32, 33], which might result from the common HLA-DR haplotypes for RA [34]. Some patients with HBV infection who fulfilled the 1987 ACR criteria for RA could have symptoms resolved by antiHBV treatment $[9,10]$. Furthermore, a recent large study from Taiwan demonstrated that patients with RA had a higher HBV period prevalence than did the nonRA subjects [11]. Results in the present study showed that patients with RA with $\mathrm{CHB}$ had more pronounced one-year radiographic progression and achieved a lower level of clinical response than the non-CHB group, which was in accordance with most previously proposed hypotheses of HBV infection acting as an adverse factor in RA.

Previous studies have shown that even though some patients with $\mathrm{HBV}$ infection may have long-lasting polyarthritis, joint destruction remains an almost rare complication. However, a case report describes a patient with positive HBsAg and HBeAg in serum, who suffered worsened pain after a steroid injection for knee osteoarthritis. Radiographs on admission showed a large bone defect in the medial tibia and slight narrowing of the articular gap. Further analysis revealed diffuse expression of HBsAg in the synovium, suggesting destructive knee arthropathy possibly caused by HBV infection [7]. Another report demonstrated that a woman with acute RA onset after receiving the first dose of HBV vaccine experienced erosions with minimal periarticular osteoporosis 10 months later [35]. In this study, a larger proportion of patients with $\mathrm{CHB}$ suffered one-year radiographic progression, which 


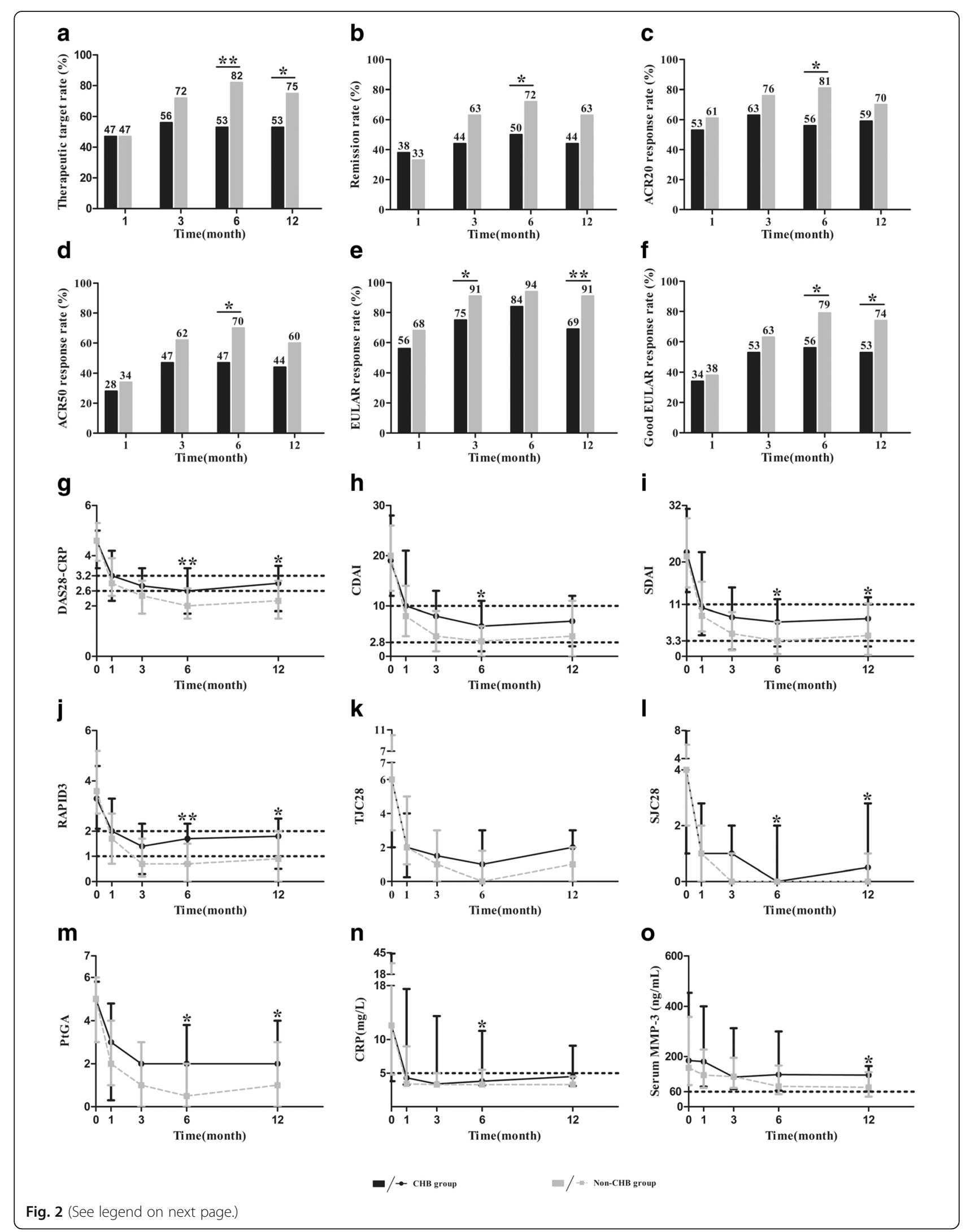


(See figure on previous page.)

Fig. 2 Clinical responses in the chronic hepatitis B virus infection (CHB) group and the non-CHB group. a-f Comparison of the rates of patients achieving therapeutic target, remission, American College of Rheumatology (ACR)20/50 responses, and European League Against Rheumatism (EULAR) responses at each visit. g-n Comparison of dynamic disease activity indicators at each visit. o Comparison of dynamic matrix metalloproteinase-3 (MMP-3) levels in female patients at each visit. Data are represented by the median and interquartile range: ${ }^{*} p<0.05,{ }^{* *} p<0.01,{ }^{* * *} p<0.001$. CDAl, Clinical Disease Activity Index; CRP, C-reactive protein; DAS28, Disease Activity Score 28-joint assessment; Pain VAS, pain visual analog scale; PrGA, provider global assessment of disease activity; PtGA, patient global assessment of disease activity; RAPID3, Routine Assessment of Patient Index Data 3; SDAI, Simplified Disease Activity Index; SJC28, 28-joint swollen joint counts; TJC28, 28-joint tender joint counts

implies that HBV infection might directly or indirectly contribute to joint damage. On the other hand, MMP-3 is a proteinase secreted by synovial fibroblasts and chondrocytes in joints, which can accelerate joint destruction in RA. Recently, the reduction in serum MMP-3 was considered as a possible therapeutic target together with disease activity. Urata et al. reported that treating to target MMP-3 normalization combined with disease activity yielded better effects than each target alone in patients with RA [36].

Our previous studies also have shown that serum MMP-3 level was positively correlated with disease activity and continuously elevated serum MMP-3 for 3 to 6 months could predict one-year radiographic progression $[17,23]$. In this study, compared with the non-CHB group, serum MMP-3 level was higher in the $\mathrm{CHB}$ group at month 6, and was significantly higher in women from the $\mathrm{CHB}$ group at month 12 , which further confirmed that patients with RA with $\mathrm{CHB}$ had a lower level of clinical response and radiographic outcome. Moreover, studies have revealed that HBV X protein could promote cell migration by inducing the transcription, translation, and secretion of MMP-3 [37]. In this scenario, it is possible that $\mathrm{CHB}$ status may negatively affect the radiographic and clinical outcomes of patients with RA partly through upregulating MMP-3. Both ACR and EULAR recommendations for the management of RA emphasize tight control of disease activity and therapeutic target should be attained within 6 months [19, 21]. Patients with $\mathrm{CHB}$ in this study had more pronounced one-year radiographic progression probably due to a lower level of clinical response during one-year follow up, especially within 6 months. That is, HBV infection may act as a "regulatory factor" or even a "driver factor" during disease progression in patients with RA with CHB. Therefore, it could be speculated that patients with $\mathrm{CHB}$ could be classified as having a specific phenotype of RA that may need adjusted regimens or routes of administration to achieve sufficient therapeutic response.

$\mathrm{HBV}$ reactivation is a well-recognized complication that may cause high morbidity and mortality in patients who undergo immunosuppressive therapy. The 2008 ACR recommended that SSZ under antiviral prophylaxis and HCQ could be used for patients with RA with $\mathrm{CHB}$ and liver function of Child-Pugh class
A, while MTX and LEF were contraindicated for all Child-Pugh classifications $[19,21]$. However, the guidelines for antiviral prophylaxis made by the American Gastroenterological Association in 2015 recommended low-dose GC therapy (prednisone (or equivalent) at < $10 \mathrm{mg} /$ day) for $>4$ weeks in the moderate-risk group and MTX in the low-risk group for HBV reactivation in patients with CHB [30]. LEF is not recommended in patients with a history of hepatitis and might increase the risk of $\mathrm{HBV}$ reactivation [14, 38]. In the present study, although not all patients with $\mathrm{CHB}$ agreed to receive recommended antiviral prophylaxis due to economic reasons, there was no significant difference in RA treatment between patients with and without antiviral prophylaxis. However, there were significant differences in the medications taken by patients with and without $\mathrm{CHB}$. Patients with $\mathrm{RA}$ with $\mathrm{CHB}$ were more likely to use SSZ and HCQ rather than LEF, and received significantly lower cumulative doses of MTX. Accordingly, a significantly greater proportion of patients with $\mathrm{CHB}$ used the regimen of MTX combined with SSZ and HCQ, while a smaller percentage of patients with CHB used the regimen of MTX combined with LEF. Nevertheless, patients with $\mathrm{CHB}$ had a significantly higher possibility of $\mathrm{HBV}$ reactivation compared to the non- $\mathrm{CHB}$ group (including patients with resolved $\mathrm{HBV}$ infection or patients never infected with $\mathrm{HBV}$ ), which may preclude escalation of therapy and might result in not reaching a full dose of some of the drugs and not achieving therapeutic target within the recommended time frame.

Multivariate logistic regression analysis revealed that both CHB status and MTX therapy were independently associated with failure to achieve therapeutic target within 6 months. Hence, it is reasonable to speculate that patients with $\mathrm{CHB}$ had more pronounced one-year radiographic progression and a lower level of clinical response probably due to both $\mathrm{CHB}$ status and different regimens, especially MTX therapy, used in the patients with $\mathrm{CHB}$. In light of the pros and cons, it is indeed difficult to find a balance during RA treatment. Therefore, besides $\mathrm{CHB}$ status, regimen adjustments for preventing $\mathrm{HBV}$ reactivation during $\mathrm{RA}$ treatment might also explain part of the adverse role of HBV infection in RA radiographic and clinical outcomes. On the other hand, 
Table 3 Logistic regression analyses of risk factors for one-year radiographic progression

\begin{tabular}{|c|c|c|c|}
\hline & OR & $95 \% \mathrm{Cl}$ & $p$ value $^{*}$ \\
\hline \multicolumn{4}{|l|}{ Univariate analyses } \\
\hline Female & 0.845 & $(0.373-1.915)$ & 0.687 \\
\hline Age & 0.993 & (0.969-1.018) & 0.598 \\
\hline Disease duration & 1.004 & $(1.000-1.008)$ & 0.076 \\
\hline CHB status & 3.129 & $(1.661-5.895)$ & $<0.001$ \\
\hline TJC28 & 0.996 & $(0.934-1.063)$ & 0.914 \\
\hline SJC28 & 0.982 & $(0.908-1.062)$ & 0.651 \\
\hline Pain VAS & 1.056 & $(0.905-1.232)$ & 0.491 \\
\hline PtGA & 1.094 & $(0.939-1.274)$ & 0.248 \\
\hline PrGA & 1.086 & $(0.921-1.281)$ & 0.326 \\
\hline $\mathrm{HAQ}$ & 1.346 & $(0.990-1.830)$ & 0.058 \\
\hline CRP & 1.001 & $(0.998-1.014)$ & 0.876 \\
\hline ESR & 0.999 & $(0.989-1.008)$ & 0.786 \\
\hline RF positivity & 2.355 & $(0.921-6.023)$ & 0.074 \\
\hline ACPA positivity & 1.983 & $(0.775-5.070)$ & 0.153 \\
\hline DAS28-CRP & 1.011 & $(0.742-1.378)$ & 0.944 \\
\hline MMP-3 & 1.001 & $(0.999-1.002)$ & 0.292 \\
\hline mTSS & 1.016 & $(1.006-1.026)$ & 0.001 \\
\hline Treatment-naïve ${ }^{\mathrm{b}}$ & 0.710 & $(0.365-1.381)$ & 0.313 \\
\hline GCs & 2.300 & $(0.964-5.489)$ & 0.061 \\
\hline MTX & 1.369 & $(0.330-5.678)$ & 0.666 \\
\hline LEF & 0.684 & $(0.359-1.304)$ & 0.248 \\
\hline SSZ & 1.984 & $(0.876-4.495)$ & 0.101 \\
\hline $\mathrm{HCQ}$ & 1.611 & $(0.828-3.135)$ & 0.160 \\
\hline CysA & 1.591 & $(0.490-5.167)$ & 0.440 \\
\hline Iguratimod & 1.130 & $(0.348-3.670)$ & 0.839 \\
\hline Biologic agents & 0.477 & $(0.200-1.139)$ & 0.095 \\
\hline $\begin{array}{l}\text { MTX combined with SSZ } \\
\text { and HCQ }\end{array}$ & 2.265 & $(0.949-5.406)$ & 0.066 \\
\hline MTX combined with LEF & 0.719 & $(0.384-1.346)$ & 0.302 \\
\hline $\begin{array}{l}\text { One-year cumulative dose } \\
\text { of } \mathrm{GC} \mathrm{s}^{\mathrm{c}}\end{array}$ & 1.000 & $(1.000-1.000)$ & 0.010 \\
\hline $\begin{array}{l}\text { One-year cumulative dose } \\
\text { of MTX }\end{array}$ & 0.999 & $(0.998-1.000)$ & 0.224 \\
\hline $\begin{array}{l}\text { One-year cumulative dose } \\
\text { of LEF }^{d}\end{array}$ & 1.000 & $(1.000-1.000)$ & 0.074 \\
\hline $\begin{array}{l}\text { One-year cumulative dose } \\
\text { of SSZ }\end{array}$ & 1.001 & $(1.000-1.003)$ & 0.133 \\
\hline $\begin{array}{l}\text { One-year cumulative dose } \\
\text { of HCQ }\end{array}$ & 1.004 & $(0.998-1.009)$ & 0.160 \\
\hline $\begin{array}{l}\text { One-year cumulative dose } \\
\text { of CysA }\end{array}$ & 1.000 & $(1.000-1.000)$ & 0.124 \\
\hline $\begin{array}{l}\text { One-year cumulative dose } \\
\text { of iguratimod }^{f}\end{array}$ & 1.000 & $(1.000-1.000)$ & 0.761 \\
\hline One-year cumulative dose & 1.000 & $(0.999-1.000)$ & 0.232 \\
\hline
\end{tabular}

Table 3 Logistic regression analyses of risk factors for one-year radiographic progression (Continued)

\begin{tabular}{|c|c|c|c|}
\hline & OR & $95 \% \mathrm{Cl}$ & $p$ value $^{*}$ \\
\hline $\begin{array}{l}\text { One-year cumulative dose } \\
\text { of Yi Sai Pu }\end{array}$ & 1.000 & $(0.998-1.003)$ & 0.817 \\
\hline $\begin{array}{l}\text { One-year cumulative dose } \\
\text { of infliximab }\end{array}$ & 0.997 & $(0.989-1.006)$ & 0.564 \\
\hline \multicolumn{4}{|l|}{ Bivariate models } \\
\hline $\begin{array}{l}\text { CHB status adjusted for } \\
\text { baseline mTSS }\end{array}$ & 2.610 & $(1.338-5.092)$ & 0.005 \\
\hline $\begin{array}{l}\text { CHB status adjusted for } \\
\text { one-year cumulative dose } \\
\text { of GCs }\end{array}$ & 2.881 & $(1.511-5.493)$ & 0.001 \\
\hline \multicolumn{4}{|l|}{ Multivariate model } \\
\hline $\begin{array}{l}\text { CHB status adjusted for baseline } \\
\text { mTSS and one-year cumulative } \\
\text { dose of GCs }\end{array}$ & 2.403 & $(1.218-4.743)$ & 0.011 \\
\hline
\end{tabular}

$A C P A$ anti-cyclic citrullinated peptide antibody, $C H B$ chronic hepatitis $B$ virus (HBV) infection, $\mathrm{Cl}$ confidence interval, $C R P$ C-reactive protein, CysA cyclosporin A, DAS28 Disease Activity Score 28-joint assessment, ESR erythrocyte sedimentation rate, GC glucocorticosteroid, HAQ Stanford Health Assessment Questionnaire, HCQ hydroxychloroquine, $L E F$

leflunomide, mTSS modified total Sharp score, MTX methotrexate, OR odds ratio, Pain VAS pain visual analog scale, PrGA provider global assessment of disease activity, PtGA patient global assessment of disease activity, $R F$ rheumatoid factor, SJC28 28-joint swollen joint count, SSZ sulfasalazine, TJC28 28-joint tender joint count

${ }^{a}$ Calculated using conditional logistic regression analysis. Univariate logistic regression analysis was performed on variables, including baseline characteristics, $\mathrm{CHB}$ status, and rheumatoid arthritis medications after enrollment (including categories of medications, one-year cumulative doses of medications, and different regimens of combined therapies); bivariate analysis was performed by adjusting for baseline mTSS and one-year cumulative dose of GCs respectively; multivariate logistic regression analysis was performed by adjusting for all significant univariate factors: bold $p$ values are significant

${ }^{b}$ Without glucocorticosteroid or DMARD therapy for 6 months

before enrollment

'One-year cumulative dose of GCs: OR 1.000282, 95\% Cl 1.000067-1.000497; $p=0.010$

${ }^{\mathrm{d}}$ One-year cumulative dose of LEF: OR 0.999888, 95\% Cl 0.999766-1.000011; $p=0.074$

eOne-year cumulative dose of CysA: OR 1.000025, 95\% Cl 0.999993-1.000057; $p=0.124$

fOne-year cumulative dose of iguratimod: OR $1.000013,95 \% \mathrm{Cl} 0.999926-$ $1.000101 ; p=0.761$

${ }^{9}$ One-year cumulative dose of tocilizumab: OR $0.999719,95 \% \mathrm{Cl} 0.999259$ $1.000180 ; p=0.232$

baseline radiographic status is an important feature that could influence radiographic progression in patients with RA. In this study, levels of JE subscore and mTSS at baseline were significantly higher in the CHB group than in the non-CHB group, and baseline mTSS was one of the significant factors for one-year radiographic progression according to the results of logistic regression analysis. However, CHB status was independently associated with one-year radiographic progression after adjusted for all confounding factors including baseline mTSS.

There are several limitations in this study. First, it was a real-world observational study from a single center and patients were treated with different medications. Although multivariate logistic regression was performed to remove the confounding effect of different 
Table 4 Logistic regression analyses of risk factors for failure to achieve therapeutic target within 6 months

\begin{tabular}{|c|c|c|c|}
\hline & OR & $95 \% \mathrm{Cl}$ & $p$ value $^{\mathrm{a}}$ \\
\hline \multicolumn{4}{|l|}{ Univariate analyses } \\
\hline Female & 1.235 & $(0.367-4.155)$ & 0.734 \\
\hline Age & 1.012 & $(0.979-1.045)$ & 0.488 \\
\hline Disease duration & 1.000 & $(0.994-1.007)$ & 0.969 \\
\hline CHB status & 3.077 & $(1.349-7.017)$ & 0.008 \\
\hline TJC28 & 1.059 & $0.986-1.137$ & 0.115 \\
\hline SJC28 & 1.035 & $0.951-1.127$ & 0.421 \\
\hline Pain VAS & 1.096 & $0.897-1.338$ & 0.369 \\
\hline PtGA & 1.192 & $0.977-1.455$ & 0.083 \\
\hline $\operatorname{PrGA}$ & 1.142 & $0.920-1.418$ & 0.230 \\
\hline $\mathrm{HAQ}$ & 1.318 & $0.880-1.975$ & 0.180 \\
\hline CRP & 1.004 & $(0.988-1.020)$ & 0.616 \\
\hline ESR & 1.000 & $(0.987-1.021)$ & 0.949 \\
\hline RF positivity & 1.637 & $(0.557-4.811)$ & 0.371 \\
\hline ACPA positivity & 0.452 & $(0.195-1.043)$ & 0.063 \\
\hline DAS28-CRP & 1.394 & $(0.936-2.077)$ & 0.102 \\
\hline MMP-3 & 1.000 & $(0.999-1.002)$ & 0.751 \\
\hline mTSS & 1.010 & $(0.995-1.024)$ & 0.195 \\
\hline Treatment-naïve ${ }^{\mathrm{b}}$ & 0.300 & $(0.102-0.881)$ & 0.029 \\
\hline GCs & 1.178 & $(0.465-2.989)$ & 0.729 \\
\hline MTX & 0.266 & $(0.099-0.716)$ & 0.009 \\
\hline LEF & 0.468 & $(0.206-1.060)$ & 0.069 \\
\hline SSZ & 1.350 & $(0.401-4.543)$ & 0.628 \\
\hline $\mathrm{HCQ}$ & 2.064 & $(0.893-4.768)$ & 0.090 \\
\hline CysA & 2.850 & $(0.847-9.591)$ & 0.091 \\
\hline Iguratimod & 2.032 & $(0.604-6.837)$ & 0.252 \\
\hline Biologic agents & 0.555 & $(0.189-1.631)$ & 0.285 \\
\hline $\begin{array}{l}\text { MTX combined with SSZ } \\
\text { and HCQ }\end{array}$ & 1.175 & $(0.275-5.009)$ & 0.828 \\
\hline MTX combined with LEF & 0.365 & $(0.155-0.861)$ & 0.021 \\
\hline $\begin{array}{l}\text { Six-month cumulative dose } \\
\text { of } G C s^{c}\end{array}$ & 1.000 & $(1.000-1.001)$ & 0.340 \\
\hline $\begin{array}{l}\text { Six-month cumulative dose } \\
\text { of MTX }\end{array}$ & 0.997 & $(0.993-1.000)$ & 0.049 \\
\hline $\begin{array}{l}\text { Six-month cumulative dose } \\
\text { of } L E F^{d}\end{array}$ & 1.000 & $(0.999-1.000)$ & 0.113 \\
\hline $\begin{array}{l}\text { Six-month cumulative dose } \\
\text { of SSZ }\end{array}$ & 1.000 & $(0.995-1.005)$ & 0.890 \\
\hline $\begin{array}{l}\text { Six-month cumulative dose } \\
\text { of } \mathrm{HCQ}\end{array}$ & 1.008 & $(0.994-1.022)$ & 0.245 \\
\hline $\begin{array}{l}\text { Six-month cumulative dose } \\
\text { of Cys } A^{e}\end{array}$ & 1.000 & $(1.000-1.000)$ & 0.023 \\
\hline $\begin{array}{l}\text { Six-month cumulative dose } \\
\text { of iguratimod }^{f}\end{array}$ & 1.000 & $(1.000-1.000)$ & 0.259 \\
\hline Six-month cumulative dose & 1.000 & $(0.999-1.000)$ & 0.337 \\
\hline
\end{tabular}

Table 4 Logistic regression analyses of risk factors for failure to achieve therapeutic target within 6 months (Continued)

\begin{tabular}{|c|c|c|c|}
\hline & OR & $95 \% \mathrm{Cl}$ & $p$ value $^{a}$ \\
\hline $\begin{array}{l}\text { Six-month cumulative dose } \\
\text { of Yi Sai Pu }\end{array}$ & 1.001 & $(0.999-1.004)$ & 0.322 \\
\hline $\begin{array}{l}\text { Six-month cumulative dose } \\
\text { of infliximab }\end{array}$ & 0.997 & $(0.986-1.009)$ & 0.659 \\
\hline \multicolumn{4}{|l|}{ Bivariate models } \\
\hline $\begin{array}{l}\text { CHB status adjusted for } \\
\text { treatment-naïve status }\end{array}$ & 2.844 & $(1.245-6.498)$ & 0.013 \\
\hline CHB status adjusted for MTX & 2.722 & $(1.177-6.298)$ & 0.019 \\
\hline $\begin{array}{l}\text { CHB status adjusted for the } \\
\text { regimen of MTX combined } \\
\text { with LEF }\end{array}$ & 3.077 & $(1.349-7.017)$ & 0.008 \\
\hline $\begin{array}{l}\text { CHB status adjusted for } 6 \text {-month } \\
\text { cumulative dose of MTX }\end{array}$ & 3.077 & $(1.349-7.017)$ & 0.008 \\
\hline $\begin{array}{l}\text { CHB status adjusted for 6-month } \\
\text { cumulative dose of CysA }\end{array}$ & 3.077 & $(1.349-7.017)$ & 0.008 \\
\hline \multicolumn{4}{|l|}{ Multivariate models } \\
\hline $\begin{array}{l}\text { CHB status adjusted for } \\
\text { treatment-naïve status, MTX therapy, } \\
\text { the regimen of MTX combined with } \\
\text { LEF, and 6-month cumulative dose } \\
\text { of CysA }\end{array}$ & 2.617 & $(1.140-6.007)$ & 0.023 \\
\hline $\begin{array}{l}\text { CHB status adjusted for treatment- } \\
\text { naïve status, } 6 \text {-month cumulative } \\
\text { dose of MTX, the regimen of MTX } \\
\text { combined with LEF, and } 6 \text {-month } \\
\text { cumulative dose of CysA }\end{array}$ & 2.844 & $(1.245-6.498)$ & 0.013 \\
\hline
\end{tabular}

ACPA anti-cyclic citrullinated peptide antibody, $C H B$ chronic hepatitis B (HBV) infection, Cl confidence interval, CRP C-reactive protein, CysA cyclosporin A, DAS28 Disease Activity Score 28-joint assessment, ESR erythrocyte sedimentation rate, GCs glucocorticosteroids, HAQ Stanford Health Assessment Questionnaire, HCQ hydroxychloroquine, LEF leflunomide, $m T S S$ modified total Sharp score, MTX methotrexate, OR odds ratio, Pain VAS pain visual analogue scale, $\operatorname{PrGA}$ provider global assessment of disease activity, PtGA patient global assessment of disease activity, $R F$ rheumatoid factor, SJC28 28-joint swollen joint count, SSZ sulfasalazine, TJC28 28-joint tender joint count

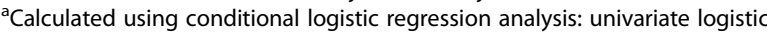
regression analysis was performed on variables, including baseline characteristics, CHB status, and rheumatoid arthritis medications after enrollment (including categories of medications, 6-month cumulative doses of medications, and different regimens of combined therapies); bivariate analysis was performed by adjusting for the significant univariate factors individually; due to the multicollinearity between MTX therapy and 6-month cumulative dose of MTX, two multivariate models (MTX therapy model and 6-month cumulative dose of MTX model) were set up respectively by adjusting for all significant univariate factors: bold $p$ values are significant

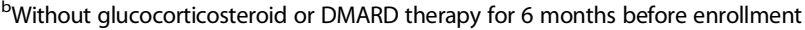
'Six-month cumulative dose of GCs: OR 1.000220, 95\% Cl 0.999768-1.000671; $p=0.340$

${ }^{\mathrm{d}}$ Six-month cumulative dose of LEF: OR $0.999738,95 \% \mathrm{Cl} 0.999414-1.000062 ; p$ $=0.113$

${ }^{\mathrm{e}} \mathrm{Six}$-month cumulative dose of CysA: OR 1.000077, 95\% Cl 1.000011-1.000143; $p=0.023$

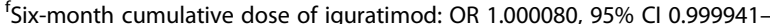
$1.000218 ; p=0.259$

${ }^{9}$ Six-month cumulative dose of tocilizumab: OR $0.999656,95 \% \mathrm{Cl} 0.998954-$ $1.000358 ; p=0.337$

medications, it would be necessary to carry out further multicenter studies and balance the combined therapy between groups. Second, over $70 \%$ of patients suffered bony erosion at baseline in this study, which was a risk 
Table 5 Safety profile of rheumatoid arthritis treatment

\begin{tabular}{llll}
\hline Side effect & $\begin{array}{l}\text { CHB group } \\
(\mathrm{n}=32)\end{array}$ & $\begin{array}{l}\text { Non-CHB group } \\
(\mathrm{n}=128)\end{array}$ & $p$ value \\
\hline Total side effects, $n(\%)$ & $15(47)$ & $68(53)$ & 0.572 \\
Infections & $5(16)$ & $16(13)$ & 0.676 \\
Gastrointestinal discomfort & $7(22)$ & $22(17)$ & 0.583 \\
Trichomadesis & $2(6)$ & $13(10)$ & 0.547 \\
Neutropenia & $2(6)$ & $14(11)$ & 0.484 \\
Aminotransferase elevation & $6(19)$ & $39(30)$ & 0.244 \\
$\quad<$ two fold ULN & $4(13)$ & $30(23)$ & 0.234 \\
$\quad \geq$ two fold, $<$ three fold ULN & $1(3)$ & $7(6)$ & 0.630 \\
$\quad \geq$ three fold ULN & $1(3)$ & $2(2)$ & 0.606 \\
Antiviral prophylaxis & $14(44)$ & $0(0)$ & NA \\
HBV reactivation & $11(34)$ & $0(0)$ & NA \\
Antiviral prophylaxis (+) & $3(9)$ & $0(0)$ & NA \\
Antiviral prophylaxis (-) & $8(25)$ & $0(0)$ & NA \\
\hline
\end{tabular}

CHB chronic HBV infection, HBV hepatitis B virus, NA not applicable, ULN upper limit of the normal range

${ }^{a}$ Compared between the CHB group and the non-CHB group using conditional logistic regression analysis

factor for one-year radiographic progression. Hence, more patients with early RA without baseline bony erosion are needed in future to confirm our results. Third, the relatively small number of patients with RA with $\mathrm{CHB}$ in this study precluded a robust conclusion. Whether clearance of HBV would lead to a good therapeutic response in RA remains to be clarified in a larger, placebo-controlled study.

\section{Conclusions}

Our results showed that patients with RA with $\mathrm{CHB}$ had more pronounced one-year radiographic progression and achieved a lower level of clinical response than those without $\mathrm{CHB}$. HBV reactivation remained a tricky issue in patients with $\mathrm{CHB}$ during RA treatment. Thus, HBV infection may play a deleterious role in radiographic and clinical outcomes among patients with RA, and HBV reactivation should be paid close attention during immunosuppressive therapy.

\section{Additional files}

Additional file 1: The other clinical responses between the CHB group and the non-CHB group. Comparison of the other clinical responses at each visit, including ACR70, PrGA, Pain VAS, HAQ, ESR, and serum MMP-3 levels. ACR: American College of Rheumatology; CHB: chronic HBV infection; ESR: erythrocyte sedimentation rate; HAQ: Stanford Health Assessment Questionnaire; MMP-3: matrix metalloproteinase-3; Pain VAS: pain visual analog scale; PrGA: provider global assessment of disease activity. (PDF $1468 \mathrm{~kb})$

Additional file 2: A flowchart of HBV reactivation occurring in patients with RA with CHB showing antiviral prophylaxis, HBV reactivation, and hepatitis flare in these patients during one-year follow up. CHB: chronic HBV infection; HBV: hepatitis B virus; RA: rheumatoid arthritis. (PDF 33 kb)

\section{Abbreviations}

ACPA: Anti-cyclic citrullinated peptide antibody; ACR: American College of Rheumatology; ALT: Alanine aminotransferase; AST: Aspartate transaminase; CDAl: Clinical Disease Activity Index; CHB: Chronic hepatitis B virus infection; $\mathrm{Cl}$ : Confidence interval; CRP: C-reactive protein; CysA: Cyclosporin A; DAS28: Disease Activity Score 28-joint assessment; DMARD: Diseasemodifying anti-rheumatic drug; ESR: Erythrocyte sedimentation rate; EULAR: European League Against Rheumatism; GC: Glucocorticosteroid; HAQ: Stanford Health Assessment Questionnaire; HBcAg: Hepatitis B virus core antigen; HBeAg: Hepatitis B virus e antigen; HBsAg: Hepatitis B virus surface antigen; HBV: Hepatitis B virus; HCQ: Hydroxychloroquine; IQR: Interquartile range; JE: Joint erosion; JSN: Joint space narrowing; LEF: Leflunomide; MMP-3: Matrix metalloproteinase-3; mTSS: Modified total Sharp score; MTX: Methotrexate; NA: Not applicable; OR: Odds ratio; Pain VAS: Pain visual analog scale; PrGA: Provider global assessment of disease activity; PtGA: Patient global assessment of disease activity; RA: Rheumatoid arthritis; RAPID3: Routine Assessment of Patient Index Data 3;

RF: Rheumatoid factor; RRP: Rapid radiographic progression; SDAl: Simplified Disease Activity Index; SJC28: 28-Joint swollen joint counts; SSZ: Sulfasalazine; TJC28: 28-Joint tender joint counts; ULN: Upper limit of the normal range

\section{Acknowledgements}

The authors wish to thank the patients and medical staff for their contribution to the study, and Nan Li from Perking University Third Hospital and Yan-Fang Ye from Sun Yat-Sen Memorial Hospital for their statistical assistance.

\section{Funding}

This work was supported by the National Natural Science Foundation of China (grant numbers 81471597, 81671612, and 81601427), Guangdong Natural Science Foundation (grant numbers 2014A030313074, 2016A030313307, and 2017A030313576), Guangdong Medical Scientific Research Foundation (grant number A2017109), and Key Program of Young Teachers Foundation of Sun Yat-sen University (grant number 17ykjc12).

\section{Availability of data and materials}

The datasets used and/or analyzed during the current study are available from the corresponding author on reasonable request.

\section{Authors' contributions}

All authors contributed to the final manuscript. Y-LC conceived and designed the study, analyzed the data, and drafted the manuscript. Corresponding authors LD and D-HZ conceived and participated in the study, read and analyzed documents, and revised the manuscript. J-ZL and Y-QM participated in clinical assessment at each visit during the follow up. Q-HL, X-YW, and TY collected and analyzed the data. J-DM and Z-HY performed the radiographic assessment. All authors have read and approved the final submitted version.

\section{Ethics approval and consent to participate}

This study was conducted in compliance with the Helsinki Declaration. Due to the retrospective nature of the study, informed consent was waived. The study was approved by the Medical Ethics Committee of Sun Yat-Sen Memorial Hospital (identifier SYSEC-KY-KS-011).

\section{Consent for publication}

All participants have approved publication of the data in this manuscript.

\section{Competing interests}

The authors declare that they have no competing interests.

\section{Publisher's Note}

Springer Nature remains neutral with regard to jurisdictional claims in published maps and institutional affiliations.

\section{Author details}

'Department of Rheumatology, Sun Yat-Sen Memorial Hospital, Sun Yat-Sen University, Guangzhou 510120, People's Republic of China. ²Department of Radiology, Sun Yat-Sen Memorial Hospital, Sun Yat-Sen University, Guangzhou, People's Republic of China. ${ }^{3}$ Zhongshan School of Medicine, Sun Yat-sen University, Guangzhou, People's Republic of China. 
Received: 24 October 2017 Accepted: 19 February 2018

\section{Published online: 02 May 2018}

\section{References}

1. Mclnnes IB, Schett $G$. The pathogenesis of rheumatoid arthritis. N Engl J Med. 2011:365(23):2205-19.

2. Ebringer A, Wilson C. HLA molecules, bacteria and autoimmunity. J Med Microbiol. 2000;49(4):305-11.

3. Zhang X, Zhang D, Jia H, Feng Q, Wang D, Liang D, et al. The oral and gut microbiomes are perturbed in rheumatoid arthritis and partly normalized after treatment. Nat Med. 2015;21(8):895-905.

4. Schweitzer A, Horn J, Mikolajczyk RT, Krause G, Ott JJ. Estimations of worldwide prevalence of chronic hepatitis B virus infection: a systematic review of data published between 1965 and 2013. Lancet. 2015;386(10003): 1546-55.

5. Terrier B, Cacoub P. Hepatitis B virus, extrahepatic immunologic manifestations and risk of viral reactivation. Rev Med Interne. 2011;32(10):622-7.

6. Mason A, Theal J, Bain V, Adams E, Perrillo R. Hepatitis B virus replication in damaged endothelial tissues of patients with extrahepatic disease. Am J Gastroenterol. 2005;100:972-6.

7. Momohara S, Okamoto H, Tokita N, Tomatsu T, Kamatani N. Rapidly destructive knee arthropathy associated with hepatitis B. Clinical \&amp. Exp Rheumatol. 2006;24:111-2.

8. Schumacher HR, Gall EP. Arthritis in acute hepatitis and chronic active hepatitis. Pathology of the synovial membrane with evidence for the presence of Australia antigen in synovial membranes. Am J Med. 1974;57(4):655-64.

9. Csepregi A, Rojkovich B, Nemesanszky E, Poor G, Hejjas M, Horanyi M. Chronic seropositive polyarthritis associated with hepatitis B virus-induced chronic liver disease: a sequel of virus persistence. Arthritis Rheum. 2000; 43(1):232-3.

10. Scully $L$, Karayiannis $P$, Thomas $H C$. Interferon therapy is effective in treatment of hepatitis B-induced polyarthritis. Dig Dis Sci. 1992;37(11):1757-60.

11. Hsu C, Lang H, Huang K, Lin HH, Chen C. Association of rheumatoid arthritis and hepatitis B infection. Medicine. 2016;95(18):e3551.

12. Csepregi A, Nemesanszky E, Rojkovich B, Poor G. Rheumatoid arthritis and hepatitis B virus: evaluating the pathogenic link. J Rheumatol. 2001;28(3):474-7.

13. Zou C, Zhu L, Li Y, Mo Y, Zheng D, Ma J, et al. The association between hepatitis B virus infection and disease activity, synovitis, or joint destruction in rheumatoid arthritis. Clin Rheumatol. 2013;32(6):787-95.

14. $M o Y Q$, Liang $A Q, M a J D$, Chen $L F$, Zheng $D H$, Schumacher $H R$, et al. Discontinuation of antiviral prophylaxis correlates with high prevalence of hepatitis $B$ virus (HBV) reactivation in rheumatoid arthritis patients with HBV carrier state: a real-world clinical practice. BMC Musculoskelet Disord. 2014;15:449.

15. Arnett FC, Edworthy SM, Bloch DA, McShane DJ, Fries JF, Cooper NS, et al. The American Rheumatism Association 1987 revised criteria for the classification of rheumatoid arthritis. Arthritis Rheum. 1988;31(3):315-24.

16. Aletaha D, Neogi T, Silman AJ, Funovits J, Felson DT, Bingham CR, et al. 2010 Rheumatoid arthritis classification criteria: an American College of Rheumatology/European League Against Rheumatism collaborative initiative. Ann Rheum Dis. 2010;69(9):1580-8.

17. Ma J, Wei $X$, Zheng $D, M o ~ Y$, Chen $L$, Zhang $X$, et al. Continuously elevated serum matrix metalloproteinase-3 for $3 \sim 6$ months predict one-year radiographic progression in rheumatoid arthritis: a prospective cohort study. Arthritis Res Ther. 2015;17:289.

18. Smolen JS, Landewe R, Breedveld FC, Dougados M, Emery P, Gaujoux-Viala $C$, et al. EULAR recommendations for the management of rheumatoid arthritis with synthetic and biological disease-modifying antirheumatic drugs. Ann Rheum Dis. 2010;69(6):964-75.

19. Smolen JS, Landewé R, Breedveld FC, Buch M, Burmester G, Dougados M, et al. EULAR recommendations for the management of rheumatoid arthritis with synthetic and biological disease-modifying antirheumatic drugs: 2013 update. Ann Rheum Dis. 2014;73(3):492-509.

20. Saag KG, Teng GG, Patkar NM, Anuntiyo J, Finney C, Curtis JR, et al. American College of Rheumatology 2008 recommendations for the use of nonbiologic and biologic disease-modifying antirheumatic drugs in rheumatoid arthritis. Arthritis Rheum. 2008;59(6):762-84.

21. Singh JA, Furst DE, Bharat A, Curtis JR, Kavanaugh AF, Kremer JM, et al. 2012 Update of the 2008 American College of Rheumatology recommendations for the use of disease-modifying antirheumatic drugs and biologic agents in the treatment of rheumatoid arthritis. Arthritis Care Res. 2012;64(5):625-39.
22. Anderson J, Caplan L, Yazdany J, Robbins ML, Neogi T, Michaud K, et al. Rheumatoid arthritis disease activity measures: American College of Rheumatology recommendations for use in clinical practice. Arthritis Care Res (Hoboken). 2012;64(5):640-7.

23. Ma JD, Zhou JJ, Zheng DH, Chen LF, Mo YQ, Wei XN, et al. Serum matrix metalloproteinase-3 as a noninvasive biomarker of histological synovitis for diagnosis of rheumatoid arthritis. Mediators Inflamm. 2014;2014:179284.

24. van der Heijde $D$, van der Helm-van MA, Aletaha D, Bingham CO, Burmester $G R$, Dougados $M$, et al. EULAR definition of erosive disease in light of the 2010 ACR/EULAR rheumatoid arthritis classification criteria. Ann Rheum Dis. 2013;72(4):479-81.

25. Takeuchi T, Yamanaka H, Ishiguro N, Miyasaka N, Mukai M, Matsubara T, et al. Adalimumab, a human anti-TNF monoclonal antibody, outcome study for the prevention of joint damage in Japanese patients with early rheumatoid arthritis: the HOPEFUL 1 study. Ann Rheum Dis. 2014;73(3):536-43.

26. Vastesaeger N, Xu S, Aletaha D, St CE, Smolen JS. A pilot risk model for the prediction of rapid radiographic progression in rheumatoid arthritis. Rheumatology (Oxford). 2009;48(9):1114-21.

27. van Gestel AM, Prevoo ML, van't Hof MA, van Rijswijk MH, van de Putte $L B$, van Riel PL. Development and validation of the European League Against Rheumatism response criteria for rheumatoid arthritis. Comparison with the preliminary American College of Rheumatology and the World Health Organization/International League Against Rheumatism Criteria. Arthritis Rheum. 1996;39(1):34-40.

28. Gonzalez SA, Perrillo RP. Hepatitis B Virus Reactivation in the setting of cancer chemotherapy and other immunosuppressive drug therapy. Clin Infect Dis. 2016;62(Suppl 4):S306-13.

29. Vassilopoulos D, Calabrese LH. Management of rheumatic disease with comorbid HBV or HCV infection. Nat Rev Rheumatol. 2012;8:348-57.

30. Perrillo RP, Gish R, Falck-Ytter YT. American Gastroenterological Association Institute technical review on prevention and treatment of hepatitis B virus reactivation during immunosuppressive drug therapy. Gastroenterology. 2015;148(1):221-44.

31. Willson RA. Extrahepatic manifestations of chronic viral hepatitis. Am J Gastroenterol. 1997:92(1):3-17.

32. Hachulla $E$, Houvenagel $E$, Mingui $A$, Vincent $G$, Laine A. Reactive arthritis after hepatitis B vaccination. J Rheumatol. 1990;17(9):1250-1.

33. Maillefert JF, Sibilia J, Toussirot E, Vignon E, Eschard JP, Lorcerie B, et al. Rheumatic disorders developed after hepatitis B vaccination. Rheumatology (Oxford). 1999;38(10):978-83.

34. Pope JE, Stevens A, Howson W, Bell DA. The development of rheumatoid arthritis after recombinant hepatitis B vaccination. J Rheumatol. 1998;25(9): 1687-93.

35. Vautier G. Acute sero-positive rheumatoid arthritis occurring after hepatitis vaccination. Br J Rheumatol. 1994;33:991.

36. Urata Y, Uesato R, Tanaka D, Nakamura Y, Motomura S. Treating to target matrix metalloproteinase 3 normalisation together with disease activity score below 2.6 yields better effects than each alone in rheumatoid arthritis patients: T-4 Study. Ann Rheum Dis. 2012;71(4):534-40.

37. Yu FL, Liu HJ, Lee JW, Liao MH, Shih WL. Hepatitis B virus X protein promotes cell migration by inducing matrix metalloproteinase-3. J Hepatol. 2005;42(4):520-7.

38. Li EK, Tam LS, Tomlinson B. Leflunomide in the treatment of rheumatoid arthritis. Clin Ther. 2004;26(4):447-59.

\section{Submit your next manuscript to BioMed Central and we will help you at every step:}

- We accept pre-submission inquiries

- Our selector tool helps you to find the most relevant journal

- We provide round the clock customer support

- Convenient online submission

- Thorough peer review

- Inclusion in PubMed and all major indexing services

- Maximum visibility for your research

Submit your manuscript at www.biomedcentral.com/submit 